\title{
EFEITOS DE ÁGUAS RESIDUÁRIAS DE CAFÉ NO CRESCIMENTO VEGETATIVO DE CAFEEIROS EM SEU PRIMEIRO ANO
}

\author{
MOISÉS S. RIBEIRO ${ }^{1}$, LUIZ A. LIMA ${ }^{2}$, FÁBIO H. DE S. FARIA ${ }^{3}$, \\ FÁTIMA C. REZENDE ${ }^{4}$, LUCAS DO A. FARIA ${ }^{5}$
}

\begin{abstract}
RESUMO: Ao utilizar o solo como forma de tratamento e de disposição final de águas residuárias de café (ARC) e essa como fonte de água e de nutrientes para os cafeeiros, solucionam-se problemas ambientais e diminuem-se os custos de produção para o cafeicultor. Este trabalho teve por objetivo avaliar os efeitos de diferentes doses de potássio aplicadas via ARC no crescimento vegetativo de cafeeiros (Coffea arabica L.), 'Catuaí' e 'Catucaí', em seu primeiro ano, bem como o incremento de potássio e a condutividade elétrica na solução do solo. $O$ estudo foi desenvolvido em casa de vegetação do Departamento de Engenharia, na Universidade Federal de Lavras, no município de Lavras - MG. Os tratamentos foram definidos por diferentes doses de potássio $\left(\mathrm{K}^{+}\right)$: $30 \mathrm{mg} \mathrm{L}^{-1} ; 65 \mathrm{mg} \mathrm{L}^{-1} ; 100 \mathrm{mg} \mathrm{L}^{-1} ; 135 \mathrm{mg} \mathrm{L}^{-1}$, aplicadas via ARC, e pela testemunha (água de irrigação e adubação convencional). ARC com concentrações até $135 \mathrm{mg} \mathrm{L}^{-1}$ de potássio contribui para o crescimento vegetativo do cafeeiro, especificamente, altura de planta e diâmetro do ramo ortotrópico, mostrando-se igualmente, ou melhor, que a água de irrigação e potássio por meio da adubação convencional. Além disso, o aumento na concentração de potássio do solo em todos os tratamentos não foi suficiente para aumentar a condutividade elétrica em níveis que possam afetar o crescimento da planta, no período avaliado.
\end{abstract}

PALAVRAS-CHAVE: potássio, reúso, Coffea arabica L.

\section{EFFECTS OF PROCESSING COFFEE WASTEWATER ON FIRST YEAR COFFEE PLANTS GROWTH}

\begin{abstract}
Using the soil as a form of treatment and final disposal for coffee wastewater (CW), considering its water and nutrient content to the coffee, solves environmental problems and reduces production costs for coffee growers. This research had the objective to evaluate the influence of different potassium levels from WC on the growth of (Coffea arabica L.), 'Catuaí' and 'Catucaí' coffee varieties, in their fist year, as well the potassium increase and electrical conductivity in the soil solution. The experiment was carried out in a greenhouse of the Engineering Department, of Universidade Federal de Lavras, in Lavras - MG, Brazil. The treatment levels were defined as: 30 $\mathrm{mg} \mathrm{L}^{-1} ; 65 \mathrm{mg} \mathrm{L}^{-1} ; 100 \mathrm{mg} \mathrm{L}^{-1} ; 135 \mathrm{mg} \mathrm{L}^{-1}$ of potassium $\left(\mathrm{K}^{+}\right)$, applied through $\mathrm{CW}$ and the control (irrigation water and conventional fertilization). Coffee processing wastewater with concentration up to $135 \mathrm{mg} \mathrm{L}^{-1}$ of potassium contributes to coffee growth, specifically, plant height and shoot diameter, showing to be equal or even better than irrigation water and potassium via conventional fertilizers. In addition, during the period evaluated the increase in soil potassium concentration was not enough to increase electrical conductivity to levels that could affect plant growth.
\end{abstract}

KEYWORDS: potassium, reuse, Coffea arabica L.

\footnotetext{
${ }^{1}$ Eng $^{\mathrm{o}}$ Agrônomo, Doutorando em Engenharia de Água e Solo, DEG/UFLA.

${ }^{2}$ Eng $^{0}$ Agrícola, Ph.D. em Irrigação e Drenagem, Prof. Adjunto, DEG/UFLA.

${ }^{3}$ Eng $^{\mathrm{O}}$ Agrônomo, Doutorando em Engenharia de Água e Solo, Prof. Adjunto, DCA/UNIMONTES.

${ }^{4}$ Eng ${ }^{a}$ Agrícola, D.Sc. em Irrigação e Drenagem, Pesquisadora, DEG/UFLA.

${ }^{5}$ Eng $^{\mathrm{o}}$ Agrícola, Doutorando em Engenharia de Irrigação de Drenagem, ESALQ/USP.

Recebido pelo Conselho Editorial em: 8-7-2008

Aprovado pelo Conselho Editorial em: 18-9-2009
} 


\section{INTRODUÇÃO}

As águas residuárias de café (ARC), por serem ricas em material orgânico e inorgânico, podem causar grandes impactos ambientais, como a degradação ou a destruição da flora e da fauna, além de comprometer a qualidade da água e do solo (BRASIL et al., 2003; MATOS et al., 2007). Devido ao seu alto potencial de contaminação, as ARCs não podem ser lançadas em corpos hídricos sem tratamento prévio (MATOS et al., 2003).

Diversos são os métodos para o tratamento de águas residuárias ricas em material orgânico. Porém, em toda e qualquer tecnologia gerada para a disposição de resíduos orgânicos no solo, por mais modernas e complexas que sejam, jamais se deve esquecer de contemplar os riscos potenciais de contaminação ambiental. Estudos recentes indicam que a disposição de águas residuárias no solo pode aumentar a produtividade das culturas, melhorar a qualidade dos produtos colhidos, promover melhorias em algumas propriedades físicas do solo, além de possibilitar redução na poluição ambiental.

A utilização das águas residuárias tratadas na agricultura é importante não apenas por servir como fonte extra de água, mas também de nutrientes para as culturas (SANDRI et al., 2007). Quando águas residuárias são aplicadas de forma controlada na superfície do solo, ocorrem processos de depuração de natureza física, química e biológica no sistema solo-planta-água (MATOS et al., 2005; LO MONACO, 2005). Nesse contexto, as plantas desempenham papel importante, que é o de utilizar os nutrientes disponibilizados pelas águas residuárias, extraindo macro e micronutrientes, além do carbono (matéria orgânica) necessário ao seu crescimento, evitando seu acúmulo e a consequente salinização do solo e a contaminação das águas superficiais e subterrâneas (MATOS et al., 2003).

FERREIRA et al. (2006), ao avaliarem a composição química da água residuária da lavagem e despolpa de frutos do cafeeiro Conilon, encontraram valores médios de condutividade elétrica, fósforo total e potássio, respectivamente, iguais a $0,99 \mathrm{dS} \mathrm{m}{ }^{-1} ; 13,9 \mathrm{mg} \mathrm{L}^{-1}$, e $204,7 \mathrm{mg} \mathrm{L}^{-1}$. Ao considerar a importância dessas características físico-químicas da água, para a cafeicultura, suponha-se que, a partir desses resultados, entre outros encontrados na literatura, há a possibilidade de aproveitamento de nutrientes contidos na ARC para o cultivo agrícola.

Existem relatos na literatura de resultados satisfatórios de produtividade e estado nutricional (equilíbrio entre o tipo e a quantidade de nutrientes ingeridos, necessidade da planta em energia e eficiência do aproveitamento biológico dos nutrientes) quando frutíferas foram fertirrigadas com efluente de estação de tratamento, sem maiores efeitos deletérios às plantas e ao meio ambiente, além de ter havido economia de fertilizantes convencionais. Entretanto, a utilização da ARC como fonte de fertilizante para o solo deve ser feita de maneira criteriosa, para que não venha ocasionar prejuízos aos solos, afetar culturas exploradas e provocar contaminação de águas superficiais e subterrâneas (MEDEIROS et al., 2008).

De acordo com LO MONACO (2005), o potássio é o macronutriente presente em maior concentração na ARC e deve ser utilizado como referencial para o cálculo da dose de água residuária passível de ser aplicada na lavoura cafeeira, sem que haja comprometimento da qualidade ambiental e prejuízo à produtividade da cultura. Acredita-se que, caso ocorra adição de todos os fertilizantes recomendados para a cultura, excetuando-se os potássicos, que já seriam fornecidos pela água residuária, a produtividade aumentaria em relação à obtida pelas plantas tratadas com adubação química convencional (MATOS et al., 2001).

Diante de uma situação na qual se procura solucionar problemas decorrentes da elevada produção de ARC, aliada às necessidades que o cafeicultor tem em alcançar menores custos de produção na atividade, torna-se de extrema importância a utilização de ARC como fonte de água e nutrientes a partir de um manejo racional de água no solo, principalmente com relação aos riscos de salinidade do solo e contaminação ambiental. 
Este trabalho teve por objetivo avaliar os efeitos de diferentes doses de potássio aplicadas via ARC no crescimento vegetativo de cafeeiros (Coffea arabica L.), 'Catuaí' e 'Catucaí', em seu primeiro ano, assim como o incremento de potássio e a condutividade elétrica na solução do solo.

\section{MATERIAL E MÉTODOS}

O experimento foi instalado e conduzido em casa de vegetação, na área experimental do Departamento de Engenharia (DEG), da Universidade Federal de Lavras (UFLA), no município de Lavras - MG. Foram utilizadas mudas de variedades dos cafeeiros Catuaí e Catucaí, e o transplantio para os vasos ocorreu em março de 2007, quando as mesmas possuíam de 4 a 6 pares de folhas definitivas.

O delineamento estatístico utilizado foi o de blocos casualizados (DBC), e a análise de variância e as médias (classificadas pelo teste Tukey a 5\%), determinadas com o auxílio do programa estatístico Sisvar, versão 5.0 (FERREIRA, 2003).

Os dados foram submetidos aos testes de Bartlett e Shapiro-Wilk, com o objetivo de avaliar, respectivamente, a homogeneidade de variância e a normalidade da distribuição de frequência, empregando-se o programa estatístico R (R DEVELOPMENT CORE TEAM, 2008). Foram estabelecidos cinco tratamentos e quatro repetições. Os tratamentos com aplicação de ARC foram definidos por diferentes doses de potássio $\left(\mathrm{K}^{+}\right): 30 \mathrm{mg} \mathrm{L}^{-1}\left(=36,14 \mathrm{mg} \mathrm{L}^{-1}\right.$ de $\left.\mathrm{K}_{2} \mathrm{O}\right) ; 65 \mathrm{mg} \mathrm{L}^{-1}$ $\left(=78,30 \mathrm{mg} \mathrm{L}^{-1} \mathrm{de} \mathrm{K}_{2} \mathrm{O}\right) ; 100 \mathrm{mg} \mathrm{L}^{-1}\left(=120,46 \mathrm{mg} \mathrm{L}^{-1}\right.$ de $\left.\mathrm{K}_{2} \mathrm{O}\right) ; 135 \mathrm{mg} \mathrm{L}^{-1}\left(=162,62 \mathrm{mg} \mathrm{L}^{-1}\right.$ de $\mathrm{K}_{2} \mathrm{O}$, dose máxima obtida pela ARC pura).

Foram feitas diluições da ARC pura com água de irrigação para a obtenção das menores doses de potássio. A testemunha foi estabelecida com água de irrigação e adubação convencional, usando fertilizantes minerais (cloreto de potássio e ureia), de acordo com o resultado analítico de fertilidade do solo (Tabela 1). O transplantio das mudas foi realizado em abril de 2007, porém os tratamentos foram aplicados a partir de setembro, quando foi disponibilizada a água residuária oriunda da colheita de café, até dezembro de 2007, período do ano em que comumente já não mais se encontra água residuária de café. A concentração de potássio na ARC foi de $135 \mathrm{mg} \mathrm{L}^{-1}$, mensurada por fotometria de chama, e a condutividade elétrica (CE) de $0,9 \mathrm{dS} \mathrm{m}^{-1}$, medida a $25^{\circ} \mathrm{C}$, por meio de condutivímetro digital. A CE da água de irrigação foi de $0,06 \mathrm{dS} \mathrm{m}^{-1}$.

O solo utilizado para preencher os vasos foi classificado como Latossolo Vermelho distroférrico típico, de acordo com EMBRAPA (1999). Foram aplicados $100 \mathrm{~g} \mathrm{vaso}^{-1}$ do composto químico referido como Fosmag, contendo as seguintes concentrações (\%): $\mathrm{P}_{2} \mathrm{O}_{5}-18,0$; Ca - 14,0; $\mathrm{Mg}-3,5 ; \mathrm{S}-10,0 ; \mathrm{Zn}-0,65 ; \mathrm{B}-0,15 ; \mathrm{Cu}-0,18$. Os fertilizantes utilizados após o plantio em todos os vasos foram: nitrogênio " $\mathrm{N}$ " (ureia: 4,45 $\mathrm{g}$ planta $^{-1}$ ) e o potássio "K" (KCl: 3,35 g planta ${ }^{-1}$ ), equivalentes a $2 \mathrm{~g}$ de $\mathrm{N}$ e $2 \mathrm{~g}$ de $\mathrm{K}_{2} \mathrm{O}\left(=1.660 \mathrm{mg}\right.$ de $\left.\mathrm{K}^{+}\right)$, respectivamente. Além dessa adubação, somente nas plantas-testemunha foram feitas mais três aplicações de $2 \mathrm{~g}$ de $\mathrm{N}$ e $2 \mathrm{~g}$ de $\mathrm{K}_{2} \mathrm{O}$, nos meses de junho, setembro e novembro de 2007. Os tratamentos com ARC não receberam nenhum tipo de fertilizante químico de setembro até o final do experimento (dezembro).

As características de crescimento vegetativo das plantas avaliadas foram: altura (AP) e diâmetro do ramo ortotrópico (DRO). Foram feitas três avaliações, em setembro, outubro e novembro.

A lâmina de água de irrigação foi calculada após mensuração da tensão de água no solo a $10 \mathrm{~cm}$ de profundidade por sensores Watermark. A quantidade de água foi determinada a partir de curva característica de água no solo, ajustada de acordo com os parâmetros empíricos da equação proposta por GENUCHTEN (1980). A irrigação foi manejada com o intuito de manter a tensão de água no solo de 10 a $20 \mathrm{kPa}$. O volume de água foi calculado considerando que cada vaso tinha $11 \mathrm{~L}$ de solo, com área superficial do solo no vaso de $0,062 \mathrm{~m}^{2}$.

A concentração de potássio $(\mathrm{K})$ e a condutividade elétrica $(\mathrm{CE})$ foram mensuradas em cada vaso antes e após o final do experimento, a fim de quantificar os impactos da aplicação da ARC. O 
potássio foi determinado por meio do extrator Mehlich e fotometria de chama. A CE dos sobrenadantes foi obtida a partir da mistura de uma parte de solo para duas e meia de água destilada (1:2,5), de acordo com RICHARDS (1954).

TABELA 1. Caracterização química do solo nos primeiros $20 \mathrm{~cm}$, antes do transplantio, coletado na área experimental do Departamento de Engenharia, na Universidade Federal de Lavras-MG. Soil chemical characterization in the first $20 \mathrm{~cm}$, before transplanting, collected in the experimental area of the Engineering Department, of Universidade Federal de Lavras - MG, Brazil.

\begin{tabular}{|c|c|c|c|c|c|c|c|c|}
\hline & & \multicolumn{7}{|c|}{ Características Físico-Químicas } \\
\hline $\mathrm{P}^{(1)}$ & $\mathrm{K}^{(\mathrm{I})}$ & $\mathrm{Ca}^{2+(2)}$ & $\mathrm{Mg}^{2+(2)}$ & $\mathrm{Al}^{3+(2)}$ & $\mathrm{H}+\mathrm{Al}^{(3)}$ & SB & $(\mathrm{t})$ & $(\mathrm{T})$ \\
\hline \multicolumn{2}{|c|}{$\mathrm{mg} \mathrm{dm}^{-3}$} & \multicolumn{7}{|c|}{$\mathrm{cmol}_{\mathrm{c}} \mathrm{dm}^{-3}$} \\
\hline 0,6 & 2 & 0,5 & 0,2 & 0,0 & 2,1 & 0,7 & 0,7 & 2,8 \\
\hline $\mathrm{V}$ & $\mathrm{m}$ & $\mathrm{Zn}^{(1)}$ & $\mathrm{Fe}^{(1)}$ & $\begin{array}{l}\mathrm{Mn}^{(1)} \\
\mathrm{mg}\end{array}$ & $\mathrm{Cu}^{(1)}$ & $\mathrm{B}^{(4)}$ & $\mathrm{S}^{(5)}$ & $\begin{array}{c}\mathrm{pH}^{(6)} \\
\mathrm{H}_{2} \mathrm{O}\end{array}$ \\
\hline 25,3 & 0 & 1,6 & 29,0 & 2,2 & 0,8 & 0,1 & 20,7 & 5,0 \\
\hline
\end{tabular}

${ }^{7}$ Extrator Mehlich 1; ${ }^{2}$ Extrator $\mathrm{KCl} 1 \mathrm{~N} ;{ }^{3}$ Extrator SMP; ${ }^{4}$ Extrator Água Quente; ${ }^{5}$ Extrator Fosfato Monocálcico em Ácido Acético; ${ }^{6} \mathrm{KCl}$ e $\mathrm{CaCl}_{2}$ - Relação 1:2,5;

\section{RESULTADOS E DISCUSSÃO}

A lâmina líquida de irrigação e a quantidade de potássio aplicada nos tratamentos em todo período considerado no estudo estão apresentadas na Tabela 2. Salienta-se que a quantidade de água variou entre tratamentos devido a diferentes valores observados de tensão de água no solo.

A temperatura mínima no interior da casa de vegetação variou de $11,4^{\circ} \mathrm{C}$ e $29,4^{\circ} \mathrm{C}$, enquanto a máxima variou de $24,1^{\circ} \mathrm{C}$ a $47^{\circ} \mathrm{C}$. Entretanto, a temperatura média no interior da casa de vegetação foi de $22,8^{\circ} \mathrm{C}$. Segundo ASSAD et al. (2004), no caso do cafeeiro da espécie Coffea arabica, temperaturas médias anuais ótimas situam-se entre $18{ }^{\circ} \mathrm{C}$ e $22^{\circ} \mathrm{C}$. Temperaturas entre $28{ }^{\circ} \mathrm{C}$ e $33^{\circ} \mathrm{C}$ provocam redução na produção de folhas e na atividade fotossintética do cafeeiro (DRINNAN \& MENZEL, 1995).

Não se sabe ao certo se os elevados valores de temperatura causaram prejuízos ao metabolismo das plantas, uma vez que não foram realizadas avaliações de variáveis relacionadas ao metabolismo dos cafeeiros, como: amido e açúcares solúveis nas folhas e nas raízes, atividade enzimática, entre outras; entretanto, a partir de análises das variáveis mensuradas, altura de planta e diâmetro de caule, como de observações visuais de sintomas de deficiência nutricional nas folhas, acredita-se que os cafeeiros não tiveram seu crescimento vegetativo prejudicado.

TABELA 2. Lâmina de irrigação (Li) e potássio (K) aplicados nos cafeeiros 'Catuaí' e 'Catucaí', localizados em casa de vegetação, na área experimental do Departamento de Engenharia, na Universidade Federal de Lavras - MG. Irrigation depth (Li) and potassium (K) applied in coffee 'Catuaí' and 'Catucaí', located in a greenhouse in the experimental area of the Engineering Department, of Universidade Federal de Lavras - MG, Brazil. ${ }^{1}$

\begin{tabular}{ccccc}
\hline \multirow{2}{*}{ Doses de Potássio $\left(\mathrm{K}^{+}\right)$} & \multicolumn{2}{c}{$\mathrm{Li}(\mathrm{mm})$} & \multicolumn{2}{c}{$\mathrm{K}\left(\mathrm{g} \mathrm{de} \mathrm{K}_{2} \mathrm{O}\right)$} \\
\cline { 2 - 5 } & Catuaí & Catucaí & Catuaí & Catucaí \\
\hline $30 \mathrm{mg} \mathrm{L}^{-1}$ & 237,3 & 355,5 & 2,5 & 2,8 \\
$65 \mathrm{mg} \mathrm{L}^{-1}$ & 235,6 & 390,7 & 3,1 & 3,9 \\
$100 \mathrm{mg} \mathrm{L}^{-1}$ & 356,3 & 255,1 & 4,6 & 3,9 \\
$135 \mathrm{mg} \mathrm{L}^{-1}$ & 400,2 & 481,2 & 6,0 & 6,8 \\
Testemunha & 336,3 & 356,5 & 8,0 & 8,0 \\
\hline
\end{tabular}

${ }^{1}$ Valores totais aplicados em todo o período experimental; os diferentes valores de lâmina de irrigação (Li) devem-se ao manejo da irrigação por sensores de tensão de água no solo. 
Quanto ao teor de potássio residual no solo ao final do experimento, verificou-se para a variedade Catuaí que não houve diferença significativa, porém tendência de maiores concentrações de potássio residual foi proporcionada pelo tratamento com $135 \mathrm{mg} \mathrm{L}^{-1}$ de potássio via ARC (Tabela 3), e não pela testemunha (adubação convencional e água de irrigação), que forneceu a maior dose de potássio ao solo. Resultados semelhantes foram encontrados por MATOS et al. (2001), em que as concentrações de potássio no solo não foram significativamente alteradas pelas diferentes doses de ARC aplicadas. Os autores aplicaram nos cafeeiros adultos, no período de junho a agosto de 2000 e 2001, ARC com concentração média $150 \mathrm{mg} \mathrm{L}^{-1}$ de potássio, nas doses de 210; 420; 840 e $1.260 \mathrm{~L} \mathrm{planta}^{-1}$, e encontraram, na camada de $10 \mathrm{~cm}$ do solo, respectivamente, concentrações médias de potássio residual de aproximadamente 44; 36; 56 e $51 \mathrm{mg} \mathrm{L}^{-1}$. Observaram-se maiores quantidades de potássio aplicadas e menores concentrações de potássio residual no solo, comparados aos resultados obtidos aqui. Porém, deve-se considerar que, no estudo em questão, o cafeeiro estava em seu primeiro ano e cultivado em vasos, o que pode ter resultado em maiores concentrações de potássio residual no solo.

Para a variedade Catucaí, a maior concentração de potássio residual no solo refere-se à aplicação de ARC com $135 \mathrm{mg} \mathrm{L}^{-1}$ de potássio, igualmente significativa apenas à testemunha (água de irrigação e adubação convencional). A maior dose de potássio aplicada propiciou maior incremento de potássio no solo ao final do experimento para as duas variedades de cafeeiro. Apesar de a adubação convencional potássica ter fornecido maior quantidade de potássio ao solo, tudo indica que tenham ocorrido maiores perdas por lixiviação. Nesse caso, todo o potássio foi aplicado em quatro vezes, diferentemente das ARCs, que forneceram o potássio paulatinamente. MATOS et al. (2005), ao utilizarem rampas vegetadas no tratamento de ARC, observaram que as concentrações de potássio no solo foram $190 \%$ maiores nas parcelas tratadas com ARC, comparadas às das parcelas tratadas com água de abastecimento e adubação convencional.

Os valores de condutividade elétrica do extrato aquoso $\left(\mathrm{CE}_{1: 2,5}\right)$, ao término do experimento, praticamente não foram diferentes estatisticamente. De modo geral, os valores de CE da ARC e a $\mathrm{CE}_{1: 2,5}$ no solo, ao final do experimento, situaram-se em níveis não prejudiciais ao crescimento vegetativo dos cafeeiros. FIGUEIRÊDO et al. (2006), ao avaliarem os efeitos de águas de irrigação com diferentes níveis de salinidade, observaram que os tratamentos com CE de 0,6 e 1,2 dS m ${ }^{-1}$ elevaram a condutividade elétrica do extrato de saturação do solo, respectivamente, para aproximadamente 5 e $8 \mathrm{dS} \mathrm{m}^{-1}$. Segundo esses autores, a água com salinidade a partir de $1,2 \mathrm{dS} \mathrm{m}^{-1}$ prejudicou o crescimento inicial do cafeeiro, tal qual o uso de água com salinidade superior a $1,8 \mathrm{dS} \mathrm{m}^{-1}$ levou o material de solo a ser classificado como salino e extremamente sódico.

MATIELLO (1999) observou que as plantas jovens suportam bem a salinidade, desde que a água não seja excessivamente salina, até $2,0 \mathrm{dS} \mathrm{\textrm {m } ^ { - 1 }}$, e que, em determinados períodos no ano, apresente boa distribuição de chuvas. KARASAWA et al. (2003), ao estudarem o desenvolvimento de mudas de cafeeiros irrigadas com águas salinas, observaram que a sensibilidade à salinidade tornou-se mais evidente quando as mudas foram irrigadas com água de $\mathrm{CE}$ igual ou maior que $0,9 \mathrm{dS} \mathrm{m}^{-1}$.

Salienta-se que, na determinação dos valores de CE do extrato aquoso obtidos neste estudo, utilizou-se água destilada na proporção 1:2,5, o que proporciona valores menores, comparados aos trabalhos que geralmente utilizam a condutividade elétrica do extrato de saturação, e, nesse caso, a proporção é de 1:1. Outro aspecto a se considerar na análise dos valores de condutividade elétrica é o cultivo dos cafeeiros em vasos, condição propensa ao maior acúmulo de sais, diferentemente do que ocorre em campo. 
TABELA 3. Concentração de potássio final no solo (K final), incremento de potássio no solo (IK) e condutividade elétrica do extrato aquoso final no solo ( $\mathrm{CE}_{1: 2,5}$ final), cultivado com os cafeeiros 'Catuaí' e 'Catucaí', localizados em casa de vegetação, na área experimental do Departamento de Engenharia, na Universidade Federal de Lavras - MG. Final Final potassium concentration in the soil $(K$ end); potassium increase in the soil (IK) and electrical conductivity of the final aqueous extract in the soil $\left(\mathrm{CE}_{1: 2,5}\right.$ final), cultivated with 'Catuaí' and 'Catucaí' coffee, located in a greenhouse in the experimental area of the Engineering Department, of Universidade Federal de Lavras - MG, Brazil. ${ }^{1}$

\begin{tabular}{crrrrrr}
\hline \multirow{2}{*}{ Doses de Potássio $\left(\mathrm{K}^{+}\right)$} & \multicolumn{2}{c}{$\mathrm{K}$ final $\left(\mathrm{mg} \mathrm{L}^{-1}\right)$} & \multicolumn{2}{c}{$\mathrm{IK}\left(\mathrm{mg} \mathrm{L}^{-1}\right)$} & \multicolumn{2}{c}{$\mathrm{CE}_{1: 2,5}$ final $\left(\mathrm{dS} \mathrm{m}^{-1}\right)$} \\
\cline { 2 - 7 } & Catuaí & Catucaí & Catuaí & Catucaí & Catuaí & Catucaí \\
\hline $30 \mathrm{mg} \mathrm{L}^{-1}$ & $106,5 \mathrm{a}$ & $93,6 \mathrm{a}$ & $79,0 \mathrm{~b}$ & $69,0 \mathrm{~b}$ & $2,9 \mathrm{a}$ & $2,2 \mathrm{ab}$ \\
$65 \mathrm{mg} \mathrm{L}^{-1}$ & $110,0 \mathrm{a}$ & $91,7 \mathrm{a}$ & $80,0 \mathrm{c}$ & $64,0 \mathrm{a}$ & $2,5 \mathrm{a}$ & $1,5 \mathrm{ab}$ \\
$100 \mathrm{mg} \mathrm{L}^{-1}$ & $118,6 \mathrm{a}$ & $91,3 \mathrm{a}$ & $80,0 \mathrm{c}$ & $70,0 \mathrm{c}$ & $2,9 \mathrm{a}$ & $1,2 \mathrm{a}$ \\
$135 \mathrm{mg} \mathrm{L}^{-1}$ & $125,2 \mathrm{a}$ & $124,1 \mathrm{~b}$ & $96,0 \mathrm{~d}$ & $102,0 \mathrm{e}$ & $2,5 \mathrm{a}$ & $2,1 \mathrm{ab}$ \\
Testemunha & $105,7 \mathrm{a}$ & $115,9 \mathrm{ab}$ & $68,0 \mathrm{a}$ & $85,0 \mathrm{~d}$ & $2,1 \mathrm{a}$ & $2,5 \mathrm{~b}$ \\
\hline
\end{tabular}

${ }^{7}$ Médias seguidas de mesma letra na coluna não diferem estatisticamente entre si, pelo teste de Tukey $(\mathrm{p}<0,05)$.

Não foi observada diferença significativa no crescimento da planta em altura (AP) quando analisadas as duas variedades (Tabela 4). Entretanto, considerando apenas a variedade Catuaí, tendência de maiores valores de AP foi verificada no tratamento com $135 \mathrm{mg} \mathrm{L}^{-1}$ de potássio e para a testemunha (água de irrigação e adubação convencional). Para a variedade Catucaí, maiores valores de AP foram observados para as plantas irrigadas com $135 \mathrm{mg} \mathrm{L}^{-1}$ e $65 \mathrm{mg} \mathrm{L}^{-1}$ de potássio. Houve tendência de a adubação convencional na variedade Catucaí causar menor crescimento de planta em altura, comparada às plantas irrigadas com ARC.

TABELA 4. Altura de planta (cm) dos cafeeiros 'Catuaí' e 'Catucaí', localizados em casa de vegetação, na área experimental do Departamento de Engenharia, na Universidade Federal de Lavras - MG. Plant height (cm) of 'Catuaí and Catucaí' coffee, located in a greenhouse in the experimental area of the Engineering Department, of Universidade Federal de Lavras - MG, Brazil. ${ }^{1}$

\begin{tabular}{ccccccc}
\hline \multirow{2}{*}{ Doses de Potássio $\left(\mathrm{K}^{+}\right)$} & \multicolumn{3}{c}{ setembro } & \multicolumn{2}{c}{ outubro } & \multicolumn{2}{c}{ novembro } \\
\cline { 2 - 6 } & Catuaí & Catucaí & Catuaí & Catucaí & Catuaí & Catucaí \\
\hline $30 \mathrm{mg} \mathrm{L}^{-1}$ & $32,0 \mathrm{a}$ & $43,0 \mathrm{a}$ & $35,6 \mathrm{a}$ & $46,6 \mathrm{a}$ & $38,9 \mathrm{a}$ & $48,0 \mathrm{a}$ \\
$65 \mathrm{mg} \mathrm{L}^{-1}$ & $33,1 \mathrm{a}$ & $45,5 \mathrm{a}$ & $35,1 \mathrm{a}$ & $50,8 \mathrm{a}$ & $37,0 \mathrm{a}$ & $51,5 \mathrm{a}$ \\
$100 \mathrm{mg} \mathrm{L}^{-1}$ & $33,8 \mathrm{a}$ & $41,8 \mathrm{a}$ & $36,4 \mathrm{a}$ & $44,9 \mathrm{a}$ & $37,4 \mathrm{a}$ & $47,0 \mathrm{a}$ \\
$135 \mathrm{mg} \mathrm{L}^{-1}$ & $35,9 \mathrm{a}$ & $47,4 \mathrm{a}$ & $40,6 \mathrm{a}$ & $50,6 \mathrm{a}$ & $41,6 \mathrm{a}$ & $53,9 \mathrm{a}$ \\
Testemunha & $36,3 \mathrm{a}$ & $42,6 \mathrm{a}$ & $40,4 \mathrm{a}$ & $44,6 \mathrm{a}$ & $41,0 \mathrm{a}$ & $46,5 \mathrm{a}$ \\
\hline
\end{tabular}

${ }^{\mathrm{T}}$ Médias seguidas de mesma letra na coluna não diferem estatisticamente entre si, pelo teste de Tukey $(\mathrm{p}<0,05)$.

Não foi verificada diferença significativa para o crescimento das plantas de Catuaí em diâmetro do ramo ortotrópico (DRO), mas, sim, tendência de maiores valores para o tratamento com $135 \mathrm{mg} \mathrm{L}^{-1}$ de potássio (Tabela 5). Para a variedade Catucaí, observou-se diferença significativa no crescimento de DRO, sendo os tratamentos com ARC, em sua maioria, os que proporcionaram maiores valores de crescimento, comparado à testemunha.

Atribui-se à tendência de maior contribuição da dose de potássio com $135 \mathrm{mg} \mathrm{L}^{-1}$ no crescimento das variáveis vegetativas, altura de planta e diâmetro de caule, de 'Catuaí' e 'Catucaí', seus consequentes e elevados teores de potássio residual e incremento de potássio, como aos valores de $\mathrm{CE}_{1: 2,5}$ no solo, aparentemente não prejudiciais aos cafeeiros. MATOS et al. (2001), ao avaliarem os efeitos da ARC sobre a produtividade dos cafeeiros, verificaram tendência de queda da mesma 
com o aumento de ARC fornecida por planta, embora aplicações de doses acima de $600 \mathrm{~L} \mathrm{planta}^{-1}$ tenham concorrido para a recuperação da produção.

MEDEIROS et al. (2008) observaram que a utilização de água residuária de origem doméstica foi mais efetiva na melhoria do estado nutricional do cafeeiro, comparada com a adubação convencional e irrigação, apesar de ambos os tratamentos não aumentarem concentrações dos macro e micronutrientes nas folhas. SOUZA et al. (2005), ao estudarem os efeitos da água residuária de origem urbana sobre a produtividade do cafeeiro, em experimento conduzido na Unidade Piloto de Tratamento de Água Residuária e Agricultura Irrigada, no Câmpus da UFV, verificaram que a água residuária não foi capaz de substituir totalmente a adubação convencional, mas mostrou-se como alternativa viável para o destino final das águas residuárias de origem doméstica, pois além de suprir as necessidades hídricas do cafeeiro, suplantaram completamente alguns nutrientes e parcialmente outros; na produtividade média bianual, não houve diferença significativa entre o manejo com água residuária e o manejo convencional.

Conforme os resultados de variáveis de crescimento obtidos neste trabalho, qualquer uma das doses de potássio via ARC aplicada aos cafeeiros favorece seu crescimento tanto em AP, quanto em DRO. Entretanto, a dose $135 \mathrm{mg} \mathrm{L}^{-1}$ de potássio mostrou-se mais tendenciosa em promover maior crescimento vegetativo dos cafeeiros.

Deve ser dada atenção à aplicação prolongada de $\mathrm{ARC}$, visto que esses resultados se baseiam apenas no primeiro ano dos cafeeiros, e o processo acumulativo de sais oriundos da ARC por um período de aplicação maior que aquele poderá elevar os teores de potássio e a condutividade elétrica do solo a níveis prejudiciais ao desenvolvimento da cultura.

TABELA 5. Diâmetro do ramo ortotrópico (mm) dos cafeeiros 'Catuaí' e 'Catucaí', localizados em casa de vegetação, na área experimental do Departamento de Engenharia, na Universidade Federal de Lavras - MG. Shoot diameter (mm) of 'Catuaí and Catucaí' coffee, located in a greenhouse in the experimental area of the Engineering Department, of Universidade Federal de Lavras - MG, Brazil. ${ }^{1}$

\begin{tabular}{ccccccc}
\hline \multirow{2}{*}{ Doses de Potássio $\left(\mathrm{K}^{+}\right)$} & \multicolumn{2}{c}{ setembro } & \multicolumn{2}{c}{ outubro } & \multicolumn{2}{c}{ novembro } \\
\cline { 2 - 7 } & Catuaí & Catucaí & Catuaí & Catucaí & Catuaí & Catucaí \\
\hline $30 \mathrm{mg} \mathrm{L}^{-1}$ & $5,0 \mathrm{a}$ & $5,5 \mathrm{a}$ & $5,5 \mathrm{a}$ & $6,5 \mathrm{abc}$ & $6,2 \mathrm{a}$ & $7,5 \mathrm{bc}$ \\
$65 \mathrm{mg} \mathrm{L}^{-1}$ & $5,4 \mathrm{a}$ & $6,0 \mathrm{a}$ & $5,8 \mathrm{a}$ & $6,8 \mathrm{bc}$ & $6,4 \mathrm{a}$ & $7,9 \mathrm{c}$ \\
$100 \mathrm{mg} \mathrm{L}^{-1}$ & $5,1 \mathrm{a}$ & $5,5 \mathrm{a}$ & $5,9 \mathrm{a}$ & $5,8 \mathrm{a}$ & $6,5 \mathrm{a}$ & $6,2 \mathrm{a}$ \\
$135 \mathrm{mg} \mathrm{L}^{-1}$ & $5,0 \mathrm{a}$ & $6,0 \mathrm{a}$ & $5,8 \mathrm{a}$ & $7,2 \mathrm{c}$ & $6,5 \mathrm{a}$ & $8,5 \mathrm{c}$ \\
Testemunha & $5,5 \mathrm{a}$ & $5,4 \mathrm{a}$ & $6,1 \mathrm{a}$ & $6,0 \mathrm{ab}$ & $6,8 \mathrm{a}$ & $6,5 \mathrm{ab}$ \\
\hline
\end{tabular}

${ }^{1}$ Médias seguidas de mesma letra na coluna não diferem estatisticamente entre si, pelo teste de Tukey $(\mathrm{p}<0,05)$.

\section{CONCLUSÕES}

A aplicação de água residuária de café nos cafeeiros 'Catuaî' e 'Catucaî' até a concentração de $135 \mathrm{mg} \mathrm{L}^{-1}$ de potássio favorece o crescimento da planta em altura e diâmetro de caule, mostrando-se igualmente, ou melhor, que a água de irrigação e a adubação convencional.

As doses de potássio até $135 \mathrm{mg} \mathrm{L}^{-1}$ aplicadas via água residuária de café promovem o incremento de potássio ao solo, sem proporcionar níveis de condutividade elétrica prejudicais aos cafeeiros, em seu primeiro ano.

Atenção deve ser dada à aplicação prolongada de água residuária de café nas doses até $135 \mathrm{mg} \mathrm{L}^{-1}$ de potássio, pois os níveis de condutividade elétrica do solo podem tornar-se prejudiciais aos cafeeiros. 


\section{AGRADECIMENTOS}

À Universidade Federal de Lavras (UFLA) e ao Programa de Pós-Graduação em Engenharia Agrícola (PPGEA) do Departamento de Engenharia (DEG), pelo apoio de seu corpo docente e de infraestrutura.

À Coordenação de Aperfeiçoamento de Pessoal de Nível Superior (CAPES) e à Fundação de Amparo à Pesquisa do Estado de Minas Gerais (FAPEMIG), pela concessão de bolsas de estudos ao longo do período experimental.

\section{REFERÊNCIAS}

ASSAD, E.D.; PINTO, H.S.; ZULLO JUNIOR, J.; HELMINSK, A.M. Impacto das mudanças climáticas no zoneamento agroclimático do café no Brasil. Pesquisa Agropecuária Brasileira, Brasília, v.39, n.11, p.1.057-1.064, 2004.

BRASIL, M. da S.; MATOS, A.T. de; FIA, R. Eficiência e impactos ambientais do tratamento de águas residuárias da lavagem e despolpa de frutos do cafeeiro em áreas alagadas naturais. Engenharia na Agricultura, Viçosa, v.11, n.1-4, p.43-51, jan./dez. 2003.

DRINNAN, J.E.; MENZEL, C.M. Temperature affects vegetative growth and flowering of coffee (Coffea arabica L.). Journal of Horticultural Science, London, v.70, n.1, p.25-34, 1995.

EMBRAPA. EMPRESA BRASILEIRA DE PESQUISA AGROPECUÁRIA. Centro Nacional de Pesquisa de Solos. Sistema brasileiro de classificação de solos. Rio de Janeiro, 1999. 412 p.

FERREIRA, D.F. Programa de análises estatísticas (statistical analysis software) e planejamento de experimentos - SISVAR 5.0 (Build 67). 2003. Disponível em:

$<$ http://www.dex.ufla.br/ danielff/softwares.htm>. Acesso em: 03 maio 2008

FERREIRA, P.A.; GARCIA, G. de O.; MATOS, A.T. de; RUIZ, H. A.; BORGES JUNIOR, J.C.F. Transporte no solo de solutos presentes na água residuária de café. Acta Scientiarum Agronomy, Maringá, v.28, n.1, p.29-35, 2006.

FIQUEIRÊDO, V.B.; FARIA, M.A. de; SILVA, E.L. da. Crescimento inicial do cafeeiro irrigado com e água salina e salinização do solo. Revista Brasileira de Engenharia Agrícola e Ambiental, Campina Grande, v.10, n.1, p.50-57, 2006.

GENUCHTEN, M.T. van. A Closed-form equation for predicting the hydraulic conductivity of unsaturated soils. Soil Science Society of American Journal, Madison, v.44, n.4, p.892-898, 1980.

KARASAWA, S.; EGUCHI, E.S.; MIRANDA, J.H.; DUARTE, S. N.; KARASAWA, M.M.G. Desenvolvimento de mudas de cafeeiro (Coffea arabica L.) irrigadas com água salina. Engenharia Rural, Piracicaba, v.14, p.1-12, 2003.

LO MONACO, P.A. Fertirrigação do cafeeiro com águas residuárias da lavagem e descascamento de seus frutos. 2005. 96 f. Tese (Doutorado em Engenharia de Água e Solo) - Universidade Federal de Viçosa, Viçosa, 2005.

MATIELLO, J.B. Evolução da salinidade e comportamento do cafeeiro em área irrigada por gotejamento em Brejões - BA. In: CONGRESSO BRASILEIRO DE PESQUISA CAFEEIRA, 25. 1999, Franca. Anais... Franca: MAPA/PROCAFÉ, 1999. p.185.

MATOS, A.T. de; EUSTÁQUIO JÚNIOR, V.; PEREIRA, P.A.; MATOS, M.P. Tratamento de água para reuso no descascamento/despolpa dos frutos do cafeeiro. Engenharia na Agricultura, Viçosa - MG, v.15, n.2, p.173-178, 2007.

MATOS, A.T. de; FIA, R.; LO MONACO, P.A. Fertirrigação da cultura do cafeeiro com águas residuárias da lavagem e despolpa de seus frutos. In: SIMPÓSIO DE PESQUISAS DOS CAFÉS DO BRASIL, 2., 2001, Vitória. Anais... Brasilia: Embrapa Café; MINASPLAN, 2001. v.2, p.13511356. 
MATOS, A.T. de; PINTO, A.B.; PEREIRA, O.G.; BARROS, F.M. Alteração de atributos químicos no solo de rampas utilizadas no tratamento de águas residuárias. Revista Brasileira de Engenharia Agrícola e Ambiental, Campina Grande, v.9, n.3, p.406-412, 2005.

MATOS, A.T. de; PINTO, A.B.; PEREIRA, O.G.; SOARES, A.A.; LO MONACO, P.A. Produtividade de forrageiras utilizadas em rampas de tratamento de águas residuárias da lavagem e despolpa dos frutos do cafeeiro. Revista Brasileira de Engenharia Agrícola e Ambiental, Campina Grande, v.7, n.1, p.154-158, 2003.

MEDEIROS, S. de S.; SOARES, A.A.; FERREIRA, P.A.; NEVES, J.C.L.; SOUZA, J.A. de. Utilização de água residuária de origem doméstica na agricultura: Estudo do estado nutricional do cafeeiro. Revista Brasileira de Engenharia Agrícola e Ambiental, Campina Grande, v.12, n.2, p.109-115, 2008.

R DEVELOPMENT CORE TEAM (2008). R: A language and environment for statistical computing. Vienna, 2008. Disponível em: <http://www.R-project.org>.

RICHARDS, L.A. (Ed.). Diagnosis and improvement of saline and alkali soils. Washington: United States Salinity Laboratory, 1954. 160 p. (Agriculture Handbook, 60).

SANDRI, D.; MATSURA, E.E.; TESTEZLAF, R. Desenvolvimento da alface Elisa em diferentes sistemas de irrigação com água residuária. Revista Brasileira de Engenharia Agrícola e Ambiental, Campina Grande, v.11, n.1, p.17-29, 2007.

SOUZA, J.A.A. de; RAMOS, M. M.; SOARES, A.A.; NEVES, J.C.L.; MEDEIROS, S. de S.; SOUZA, J.A. de. Efeitos da fertirrigação com água residuária de origem urbana sobre a produtividade do cafeeiro. Revista Brasileira de Engenharia Agrícola e Ambiental, Campina Grande, v.9, p.128-132, 2005. 